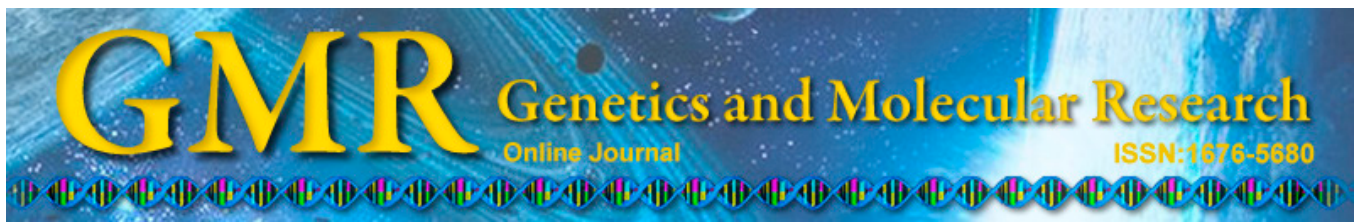

\title{
Copy number and integration sites in growth hormone transgenic goats
}

\author{
Q. Zhang, J. Lin, Q.H. Yu, W.W. Hu and Q. Yang \\ College of Veterinary, Nanjing Agricultural University, Weigang, Jiangsu, \\ China
}

Corresponding author: Q. Yang

E-mail: zxbyq@njau.edu.cn

Genet. Mol. Res. 14 (1): 2006-2014 (2015)

Received January 21, 2014

Accepted July 7, 2014

Published March 20, 2015

DOI http://dx.doi.org/10.4238/2015.March.20.10

\begin{abstract}
Transgenic goats have been utilized for years to produce valuable protein. However, when transgenic goats are produced by random integration of inserted genes into cells, the copy number and integration sites of these genes in the goat genome are typically indefinite. Most polymerase chain reaction (PCR)-based methods that have been utilized to determine copy number and integration sites of inserted genes in the genome require complicated manipulations. In this study, we used quantitative real-time PCR and thermal asymmetric interlaced-PCR to determine copy number and integration sites of the inserted genes, respectively. Copies of transgenic goat lines GHcd-2 and GHcd-7 were $12.95 \pm 0.18$ and $12.24 \pm 1.12$, respectively. Two integration sites, located in chromosomes 3 and 11 and referred to as $\operatorname{tg} 1$ and $\operatorname{tg} 2$, were identified by thermal asymmetric interlaced-PCR. Junction PCR was then performed to confirm the integration sites of growth hormone transgenic goats. Transgenic copy number and integration sites were determined, which will be useful for determining the relationship between the growth hormone expression, copy number, and integration sites.
\end{abstract}

Key words: Absolute quantitative PCR; Copy number; Transgenic goat; Integration sites; Thermal asymmetric interlaced polymerase chain reaction 


\section{INTRODUCTION}

Production of transgenic livestock has revolutionized the agricultural sciences by providing a strategy for studying the performance of the gain or loss of genes in vivo. Somatic cell nuclear transfer (SCNT) is a conventional method for gene transfer into livestock, in which foreign DNA fragments often randomly integrate into the genome of donor cell, resulting in tandem repeats encompassing several copies of exogenous genes. Additionally, random integration of exogenous gene can often cause deletions or rearrangements in the genome (Le Provost et al., 2010; Zhang et al., 2012). When new transgenic animals are produced, an essential step is to determine the copy number and insertion sites of the inserted genes in the transgenic animals. Traditionally, Southern blot analysis has been used to verify the integration of gene fragments and the transgene copy number, but this typically requires a significant amount of high-quality DNA and involves several time-consuming steps.

Based on differences between transgenic and non-transgenic animals at the DNA sequence level (target gene-specific, promoter-specific, marker gene-specific, and construct-specific), various polymerase chain reaction (PCR) methods have been developed for the analysis of transgenic organisms, including quantitative PCR (Song et al., 2002). This method of determining the transgene copy number may be used to overcome the limitations of Southern blot analysis. To date, quantitative PCR technology has been applied widely to analyze the copy number of transgenic animals, including mouse (Joshi et al., 2008; Vaisman, 2013) and pig (Watanabe et al., 2012; Ballester et al., 2013). However, thermal asymmetric interlaced PCR (TAIL-PCR), based on nest PCR and randomly primed PCR category (Liu and Chen, 2007), has become an extremely valuable and versatile tool for detecting insertion sites of foreign genes. TAIL-PCR methods have been successfully used to clone unknown sequences adjacent to known vector sequences in mice (Pillai et al., 2008, Serova et al., 2012) and pig (Zhou et al., 2013); however, there are few reports focusing on transgenic goats because the goat genome has not been completely sequenced.

In our previous studies, we generated several transgenic goat lines by SCNT, with growth hormone (GH) expression driven by the mammary-specific promoter. To further determine the inheritance and expression stability of transgenes and assess the biosafety of GH transgenic goats, we investigated the copy number and integration sites of exogenous genes in these goats.

\section{MATERIAL AND METHODS}

\section{Animals and DNA samples}

Two transgenic goat lines, GHcd-2 and GHcd-7, were previously generated by SCNT using the pcGH construct, which contained $2.3 \mathrm{~kb}$ of the goat beta-LG proximal promoter region, the coding sequence of the goat $\mathrm{GH}$, and $1.9 \mathrm{~kb}$ of the 3 ' flanking region.

Genomic DNA was extracted from whole goat blood using the Blood Genomic DNA Extraction Kit (Tiangen Biotech, Beijing, China) following manufacturer instructions. Extracted DNA was stored at $-20^{\circ} \mathrm{C}$ until use. The extracted genomic DNA was measured by electrophoresis. Gels were prepared with $1 \%$ agarose in Tris-acetate-EDTA buffer containing ethidium bromide. Genomic DNA was used as a template for quantitative PCR and TAIL-PCR.

All primers used in this study were synthesized by Invitrogen Co., Ltd. (Carlsbad, CA, USA) and are listed in Table 1. 
Table 1. Primers used in this study.

\begin{tabular}{lll}
\hline Name & Sequence $\left(5^{\prime} \rightarrow 3^{\prime}\right)$ & Orientation \\
\hline q-GHF & CCAGCTGTGCCTTCTAGGTC & Quantitative PCR \\
q-GHR & GAGGTCAGCGTGTGAGTGAG & Quantitative PCR \\
q-GAPDHF & GGGTGTTGTTATACTTCTCGTGGTT & Quantitative PCR \\
q-GAPDHR & GTGATGCTGGTGCTGAGTATGTG & Quantitative PCR \\
SP1 & GGAGTTCCGCGTTACATAACTTACG & 1st of TAIL-PCR \\
SP2 & TGACGTATGTTCCCATAGTAACGCC & 2st of TAIL-PCR \\
SP3 & CCCATAGTAACGCCAATAGGGACTT & 3st of TAIL-PCR \\
AD1 & TGCACCACTGGACTGAGCGGCCGCVNVNNNGGAA & 1st of TAIL-PCR \\
AD2 & TGCACCACTGGACTGAGCGGCCGCBNBNNNGGTT & 1st of TAIL-PCR \\
AD3 & TGCACCACTGGACTGAGCGGCCGCVVNVNNNCCAA & 1st of TAIL-PCR \\
AD4 & TGCACCACTGGACTGAGCGGCCGCVBNBNNNCGGT & 1st of TAIL-PCR \\
AC & TGCACCACTGGACTGA & 2st and 3st of TAIL-PCR \\
YZ1 & AGCTCTGCTTATATAGACCTCCCACCGTAC & Common PCR \\
YF230 & CCTTCTGCTTCTCCGAAACCATC & Junction PCR \\
YR1331 & ATCCTCTGAGCCAGACCACTCCC & Junction PCR \\
YF12 & ACAAGATGGATTGCACGCAGGTTC & Junction PCR \\
YR749 & GGAGCGGCGATACCGTAAAGCAC & Junction PCR \\
\hline
\end{tabular}

\section{Real-time reverse transcription (RT)-PCR}

To determine the copy number of the pcGH transgene in GH transgenic goats, it was essential to establish an absolute quantitative standard curve. The standard curve was established using the method described by Kong (2009). Quantitative PCR was performed using an ABI Prism 7500 sequence detection system (Applied Biosystems, Foster City, CA, USA) using SYBR Premix Ex TaqTM (TaKaRa, Shiga, Japan), with the following the parameters: $95^{\circ} \mathrm{C}$ for $10 \mathrm{~s}$, followed by 40 cycles at $95^{\circ} \mathrm{C}$ for $5 \mathrm{~s}$ and at $60^{\circ} \mathrm{C}$ for $34 \mathrm{~s}$. For quantitative PCR, primers q-GHF and q-GHR were used to amplify the GH transgene, while the glyceraldehyde 3-phosphate dehydrogenase (GAPDH) gene was amplified by primers q-GAPDHF and qGAPDHR as an endogenous control (Table 1). Ct value was calculated using the Sequence Detection System software (Applied Biosystems). A quantitative standard curve was drawn by plotting $\Delta \mathrm{Ct}(\Delta \mathrm{Ct}=\mathrm{CtGH}-\mathrm{CtGAPDH})$ against the log of $\mathrm{GH}$ transgene copies of corresponding standard samples. Copy numbers of transgenic lines were calculated using the formula. To minimize the error associated with different quantities of applied template, the PCR was repeated 3 times and the values are reported as means \pm standard error.

\section{TAIL-PCR analysis of the integration sites}

To analyze the integration sites, 3 transgene specific primers, SP1, SP2, and SP3, and 4 arbitrary degenerate primers were designed for TAIL-PCR amplification using the method described by Liu and Chen (2007) with slight modifications (Table 1). The thermal cycling conditions are summarized in Table 2. Briefly, the primary PCR contained 50-100 ng genomic DNA, $1.5 \mathrm{mM}$ dNTPs, $0.2 \mu \mathrm{M}$ SP1 primer, $2 \mu \mathrm{m}$ AD primer, and $1 \mathrm{U}$ Taq polymerase in 20 $\mu \mathrm{L} 1 \mathrm{X}$ reaction buffer. In the secondary or tertiary amplification, $0.65 \mu \mathrm{L}$ first or secondary products, respectively, were used as templates and supplemented in the reaction. The products of tertiary TAIL-PCR were separated on a $1.0 \%$ agarose gel. The bands in each goat sample were gel-purified with the Tiangen Purification Kit (Tiangen Biotech) and sequenced directly. The resulting sequences were analyzed using the DNASTAR software and online BLAST available from the NCBI database. 
Table 2. Cycling parameters and PCR conditions for TAIL-PCR.

\begin{tabular}{|c|c|c|c|}
\hline PCR system & Cycle number & Thermal conditions & Primers \\
\hline Primary & $\begin{array}{r}1 \\
6 \\
25 \\
1\end{array}$ & $\begin{array}{l}93^{\circ} \mathrm{C} 2 \mathrm{~min}, 95^{\circ} \mathrm{C} 1 \mathrm{~min}, \\
94^{\circ} \mathrm{C} 30 \mathrm{~s}, 62^{\circ} \mathrm{C} 1 \mathrm{~min}, 72^{\circ} \mathrm{C} 3 \mathrm{~min} \\
94^{\circ} \mathrm{C} 30 \mathrm{~s}, 25^{\circ} \mathrm{C} 2 \mathrm{~min}, \text { ramping to } 72^{\circ} \mathrm{C} 0.5^{\circ} \mathrm{C} / \mathrm{s} \text {, } \\
72^{\circ} \mathrm{C} 3 \mathrm{~min}, 94^{\circ} \mathrm{C} 20 \mathrm{~s}, 58^{\circ} \mathrm{C} 1 \mathrm{~min}, 72^{\circ} \mathrm{C} 3 \mathrm{~min} \\
72^{\circ} \mathrm{C} 5 \mathrm{~min}, 10^{\circ} \mathrm{C} \text { forever }\end{array}$ & $\mathrm{AD}$ and SP1 Primers \\
\hline Secondary & $\begin{array}{r}1 \\
2 \\
13\end{array}$ & $\begin{array}{l}94^{\circ} \mathrm{C} 5 \mathrm{~min} \\
94^{\circ} \mathrm{C} 20 \mathrm{~s}, 63^{\circ} \mathrm{C} 1 \mathrm{~min}, 72^{\circ} \mathrm{C} 3 \mathrm{~min} \\
94^{\circ} \mathrm{C} 20 \mathrm{~s}, 63^{\circ} \mathrm{C} 1 \mathrm{~min}, 72^{\circ} \mathrm{C} 3 \mathrm{~min}, \\
94^{\circ} \mathrm{C} 20 \mathrm{~s}, 63^{\circ} \mathrm{C} 1 \mathrm{~min}, 72^{\circ} \mathrm{C} 3 \mathrm{~min}, \\
94^{\circ} \mathrm{C} 20 \mathrm{~s}, 63^{\circ} \mathrm{C} 1 \mathrm{~min}, 72^{\circ} \mathrm{C} 3 \mathrm{~min} \\
94^{\circ} \mathrm{C} 20 \mathrm{~s}, 44^{\circ} \mathrm{C} 1 \mathrm{~min}, 72^{\circ} \mathrm{C} 3 \mathrm{~min} \\
72^{\circ} \mathrm{C} 5 \mathrm{~min}, 10^{\circ} \mathrm{C} \text { forever }\end{array}$ & $\mathrm{AC}$ and SP2 Primers \\
\hline Tertiary & $\begin{array}{l}1 \\
7\end{array}$ & $\begin{array}{l}94^{\circ} \mathrm{C} 5 \mathrm{~min} \\
94^{\circ} \mathrm{C} 20 \mathrm{~s}, 64^{\circ} \mathrm{C} 1 \mathrm{~min}, 72^{\circ} \mathrm{C} 3 \mathrm{~min} \\
94^{\circ} \mathrm{C} 20 \mathrm{~s}, 64^{\circ} \mathrm{C} 1 \mathrm{~min}, 72^{\circ} \mathrm{C} 3 \mathrm{~min}, \\
94^{\circ} \mathrm{C} 20 \mathrm{~s}, 44^{\circ} \mathrm{C} 1 \mathrm{~min}, 72^{\circ} \mathrm{C} 3 \mathrm{~min} \\
72^{\circ} \mathrm{C} 10 \mathrm{~min}\end{array}$ & AC and SP3 Primers \\
\hline
\end{tabular}

\section{RESULTS}

\section{Copy number in GH transgenic goat lines}

In order to determine the copy number of the GH gene, we generated a standard curve. In this study, a standard set of mixtures representing $0,0.5,2,4,8$, and 32 copies of the pcGH transgene were used to generate the standard curve (Figure 1). The equation of the standard curve was: $\log _{2} \mathrm{~N}=-0.9176 \Delta \mathrm{Ct}+7.1188\left(\mathrm{R}^{2}=0.9975\right)$. Further, the results showed that the copy numbers of GHcd-2 and GHcd-7 were $12.95 \pm 0.18$ and $12.24 \pm 1.12$, respectively, as calculated using this formula.
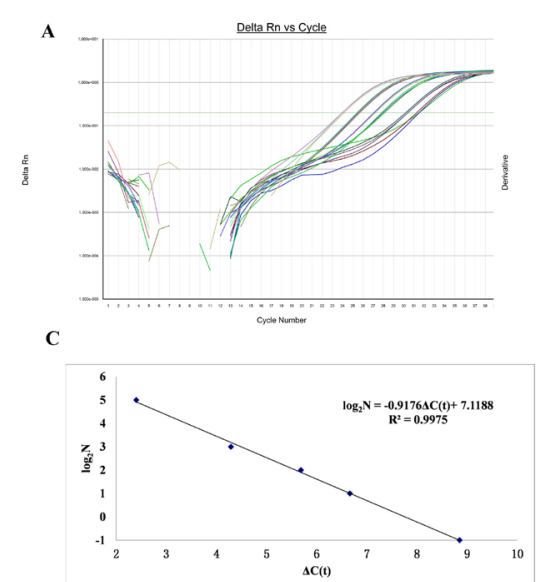

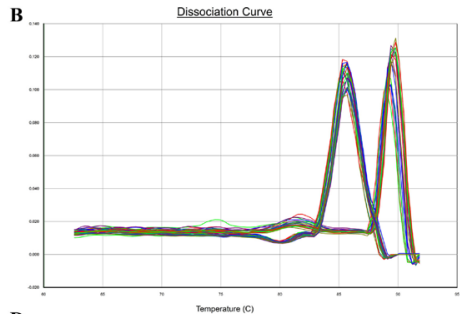

D

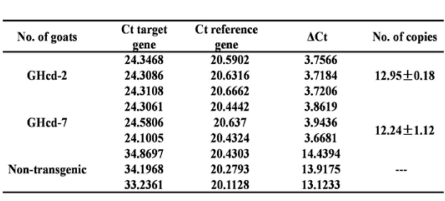

Figure 1. Determination of the copy number of GH transgenic goat lines by using quantitative PCR. A. Amplification plot of GH was generated using a standard set of mixtures that represent the pcGH transgene. B. Absolute quantitative standard curve. The standard samples containing $0,0.5,2,4,8$, and 32 copies of the GH genes were prepared. The absolute quantitative standard curve was drawn by plotting $\Delta \mathrm{Ct}(\Delta \mathrm{Ct}=\mathrm{CtGH}-\mathrm{CtGAPDH})$ against the log of GH gene copies of corresponding standard samples. C. Association curve of GH and GAPDH. D. Calculation of the copy number of GH transgene lines. 


\section{Integration of GH transgenic goat lines}

Because the integration sites of inserted genes greatly influenced the expression of inserted genes and their nearby endogenous genes, it is vital to identify gene integration sites in transgenic organisms. To identify the integration sites of the inserted genes in the goat chromosome, TAIL-PCR was used to define the 3 ' flanking boundaries of the transgene using 3 specific primers (SP1, SP2, and SP3) and 4 arbitrary degenerate primers (AD1-4) (Figure 2A). The combination of specific primer SP3 and arbitrary primers AD1 in the tertiary amplification reactions amplified a set of discrete products about approximately $0.5-2.0 \mathrm{~kb}$ in size (Figure $2 \mathrm{~B}, \mathrm{C}$ ). Following tertiary PCR, the products were gelpurified and cloned into the pMD19-T vector, which was further screened using a pair of specific primers (SP1 and YZ1) designed based on the 3' flanking sequences of the pcGH construct (Table 1). Positive recombinant plasmids containing the $170 \mathrm{bp}$ fragment were further sequenced (Figure 2D). Sequence analysis showed that the PCR products of GHcd-

A

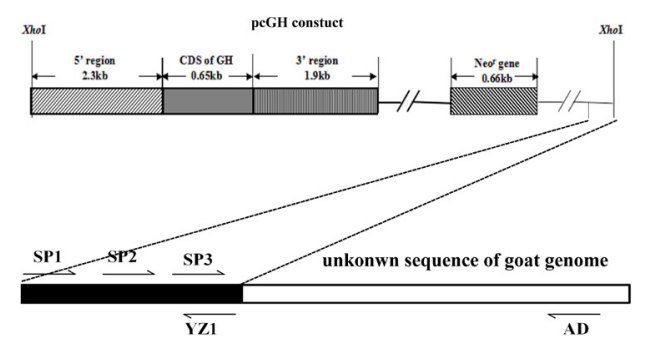

B

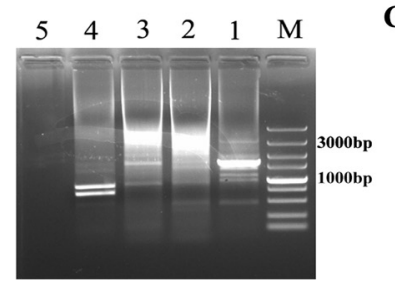

$\begin{array}{lllllll}\text { C } & 5 & 4 & 3 & 2 & 1 & \mathbf{M}\end{array}$

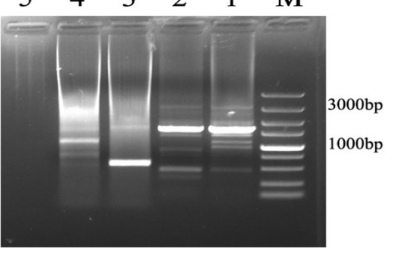

D

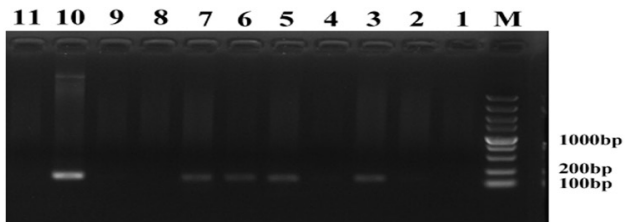

Figure 2. Integration site analysis of GH transgenic lines GHcd-2 and GHcd-7 by using TAIL-PCR. A. Schematic diagram of amplification of target sequences by using TAIL-PCR. Black box: the 3 ' flanking sequences of the vector pcGH. White box: unknown genomic sequence. SP1, SP2, and SP3: specific primers. AD: Arbitrary degenerate primers. B. Tertiary amplification of pcGH flanking sequences from the transgenic goat line GHcd-2 by using TAIL-PCR. Lanes 1, 2, 3, and 4: tertiary amplification using AD1, AD2, AD3, and AD4. Lane 5: negative control (AD primer absent). C. Tertiary amplification of pcGH flanking sequences from the transgenic goat line GHcd-7 by using TAIL-PCR. Lanes 1, 2, 3, and 4: tertiary amplification using AD1, AD2, AD3, and AD4. Lane 5: negative control (AD primer absent). D. Identification of TAIL-PCR results by using general colony PCR with a pair of primers: SP1 and YZ1. Lanes 3, 5, 6, 7, and 10: positive colonies. Lanes 1, 2, 4, 8, and 9: negative colonies. Lane 11: negative control. 
2 and GHcd-7 both contained the inserted genes from the goat genome. This sequence was $99 \%$ identical to the initial 3'-end of the inserted DNA. Because little sequence information is available for the goat genomic DNA sequence in the GenBank database, we analyzed the homology of the amplified sequence with goat genome database using BLAST. A high degree of sequence homology was observed between chromosomes 3 and 11 of goat and the amplified product. To confirm whether the cloned unknown DNA sequences originated from the goat genome, 2 specific primers YF230, YR2331 and YF12, YR749 were designed based on the 1100- and 788-bp DNA sequences (Figure 3A and B). Junction PCR was performed using the DNA from the genome of GH transgenic goat as templates. Two DNA fragments of 1101 and 737 bp were obtained from GH transgenic goat, while no amplified products were observed in non-transgenic goats.
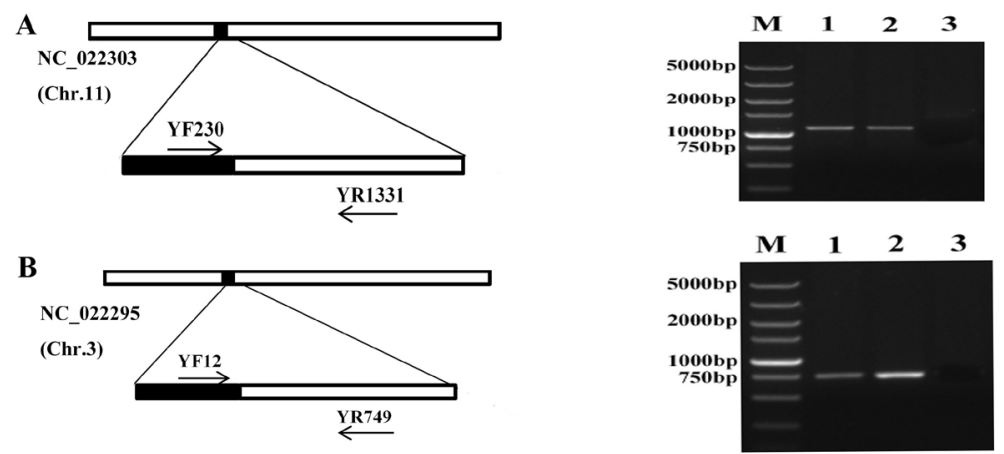

Figure 3. Verification of the integration sites of the transgene by using PCR. A. Left: schematic diagram of the integration sites, named tg1, of transgenic lines GHcd-2 and GHcd-7. Right: identification of integration sites by using PCR with primer YF230 (located at the 3' flanking region of pcGH) and YR1331 (located at the 5' flanking region of unknown genome sequences). Lane 1: GHcd-2 transgenic line. Lane 2: GHcd-7 transgenic line. Lane 3: non-transgenic goat (negative goat). B. Left: Schematic diagram of the integration sites, named tg2, of transgenic lines GHcd-2 and GHcd-7. Right: Identification of integration sites by using PCR with primer YF12 (located at the 3' flanking region of pcGH) and YR749 (located at the 5' flanking region of unknown genome sequences). Lane 1: GHcd-2 transgenic line. Lane 2: GHcd-7 transgenic line. Lane 3: non-transgenic goat (negative control).

\section{DISCUSSION}

Determining the copy number and insertion sites of genes of interest is essential for investigating the inheritance and expression stability of transgenes in transgenic goats (Van Reenen, 2009; Jackson et al., 2010). We generated several transgenic goat lines by SCNT using the pcGH construct. Because the GH transgenic line was not generated by site-specific recombination technology, the integration sites and copy numbers were uncertain, and these factors may influence the phenotype of transgenic animals (Chandler et al., 2007). Recently, because less DNA is required and because of its high sensitivity, precision, and repeatability, quantitative PCR has replaced Southern blotting for determining copy number in transgenic animals (Ballester et al., 2004; Lipinski et al., 2012). In the present study, we detected approximately 12 copies of GHcd-2 and GHcd-7 in GH transgenic goats using the quantitative PCR method. The similar copy number of the 2 transgenic goats may also indicate that the donor cells originated from the same cloned cell lines. High copy number tandem integration is thought to lead to transgene silencing (Tang et al., 2007), and high copy numbers may 
decrease in aging transgenic animals. A previous study showed that at least approximately 10 copies were ideal for analysis (Chandler et al., 2007). In our study, 12 copies of the GH transgene ensure $\mathrm{GH}$ expression in transgenic goats.

The relationship between integration sites and transgene expression is controversial. Several reports demonstrated that integration sites influence transgene expression levels (Grosveld et al., 1987; Williams et al., 2008), while in some case, integration positions have no effect on transgene expression (Wang et al., 2010). However, the inserted DNA may cause rearrangement of endogenous genes (Le Saux et al., 2010; Zhang et al., 2012) and result in genome variation. Several PCR-based methods have been described to precisely determine the integration site of exogenous DNA into native chromosomes, including inverse PCR (Wu et al., 2013), ligation-mediated PCR (Yuanxin et al., 2003), and TAIL-PCR (Yan et al., 2010, 2013). Of these methods, TAIL-PCR is very simple, efficient, and highly specific. Because no other manipulations apart from PCR are required, TAIL-PCR is particularly suitable for isolating targeted unknown sequences from a large number of samples. In this study, we used this method to explore the integration sites of the GH transgene in 2 GH transgenic goats. As described previously (Liu and Chen, 2007), selection of an optimal specific primer for primary TAIL-PCR is important for successful amplification. To adapt the TAIL-PCR technique to this system, 3 sets of specific primers with sequences flanking the 3 ' pcGH vector were designed and tested for the pcGH insert end amplification. Amplified fragments ranged in size from $0.5-2.0 \mathrm{~kb}$. Multiple bands may be observed because of low primer specificity or insertion of DNA in a head-to-tail array (Palmiter and Brinster, 1986; Garrick et al., 1998). Sequence analysis of the 3' insertion site by BLAST indicated that the transgene was integrated into the glucose transporter 1 gene (GenBank: JQ343217, identity 99\%). BLAST analysis of the goat genome database revealed that the glucose transporter 1 gene sequence in goat is located in chromosome 3 (GenBank: NC_022295, identity $100 \%)$. Another integration site was also observed in chromosome 11 (GenBank: NC_022303, identity 99\%). Amplification of 2 specific DNA fragments of 1100 and $737 \mathrm{bp}$ by junction PCR was obtained using 2 specific primers YF230, YR2331 and YF12, YR749 from the GH transgenic goat, respectively. In summary, we demonstrated the successful use of quantitative PCR and TAIL-PCR to characterize the GH transgene integration. Our results will contribute to the study of the relationship between GH expression, copy number, and integration sites.

\section{CONCLUSION}

To date, PCR-based techniques have been widely used for precise transgene flanking sequence and copy number identification in molecular biology research. We demonstrated the successful use of quantitative PCR and TAIL-PCR to characterize GH integration. We used quantitative PCR methods to determine the copy numbers of the GH gene in GH transgenic goats. Furthermore, using the TAIL-PCR approach, we identified 2 integration sites with high specificity and provided information regarding their chromosomal locations. Quantitative PCR and TAIL-PCR can be used to characterize transgenic goats.

\section{Conflicts of interest}

The authors declare no conflict of interests. 


\section{ACKNOWLEDGMENTS}

Research supported by the National Animal Transgenic Breeding Grand Project of China (\#2013ZX08008-004) and a Project Funded by the Priority Academic Program Development of Jiangsu Higher Education Institutions.

\section{REFERENCES}

Ballester M, Castelló A, Ibáñez E, Sánchez A, et al. (2004). Real-time quantitative PCR-based system for determining transgene copy number in transgenic animals. Biotechniques 37: 610-613.

Ballester M, Castelló A, Ramayo-Caldas Y and Folch JM (2013). A quantitative real-time PCR method using an X-linked gene for sex typing in pigs. Mol. Biotechnol. 54: 493-496.

Chandler KJ, Chandler RL, Broeckelmann EM, Hou Y, et al. (2007). Relevance of BAC transgene copy number in mice: transgene copy number variation across multiple transgenic lines and correlations with transgene integrity and expression. Mamm. Genome 18: 693-708.

Garrick D, Fiering S, Martin DI and Whitelaw E (1998). Repeat-induced gene silencing in mammals. Nat. Genet. 18: 56-59.

Grosveld F, van Assendelft GB, Greaves DR and Kollias G (1987). Position-independent, high-level expression of the human beta-globin gene in transgenic mice. Cell 51: 975-985.

Jackson KA, Berg JM, Murray JD and Maga EA (2010). Evaluating the fitness of human lysozyme transgenic dairy goats: growth and reproductive traits. Transgenic Res. 19: 977-986.

Joshi MU, Pittman HK, Haisch CE and Verbanac KM (2008). Real-time PCR to determine transgene copy number and to quantitate the biolocalization of adoptively transferred cells from EGFP-transgenic mice. Biotechniques 45: 247.

Kong Q, Wu M, Huan Y, Zhang L, et al. (2009). Transgene expression is associated with copy number and cytomegalovirus promoter methylation in transgenic pigs. PLoS One 4: e6679.

Le Provost F, Lillico S, Passet B, Young R, et al. (2010). Zinc finger nuclease technology heralds a new era in mammalian transgenesis. Trends Biotechnol. 28: 134-141.

Le Saux A, Houdebine LM and Jolivet G (2010). Chromosome integration of BAC (bacterial artificial chromosome): evidence of multiple rearrangements. Transgenic Res. 19: 923-931.

Lipinski D, Zeyland J, Plawski A and Slomski R (2012). Determination of the absolute number of transgene copies in Cmvfut transgenic pigs. Ann. Anim. Sci. 12: 349-356.

Liu YG and Chen Y (2007). High-efficiency thermal asymmetric interlaced PCR for amplification of unknown flanking sequences. Biotechniques 43: 649-50, 652, 654 passim.

Palmiter RD and Brinster RL (1986). Germ-line transformation of mice. Ann. Review of Genetics. 20: 465-499.

Pillai MM, Venkataraman GM, Kosak S and Torok-Storb B (2008). Integration site analysis in transgenic mice by thermal asymmetric interlaced (TAIL)-PCR: segregating multiple-integrant founder lines and determining zygosity. Transgenic Res. 17: 749-754.

Serova IA, Dvoryanchikov GA, Andreeva LE, Burkov IA, et al. (2012). A 3,387 bp 5'-flanking sequence of the goat alphaS1-casein gene provides correct tissue-specific expression of human granulocyte colony-stimulating factor (hG-CSF) in the mammary gland of transgenic mice. Transgenic Res. 21: 485-498.

Song P, Cai C, Skokut M, Kosegi B, et al. (2002). Quantitative real-time PCR as a screening tool for estimating transgene

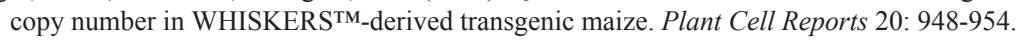

Tang W, Newton RJ and Weidner DA (2007). Genetic transformation and gene silencing mediated by multiple copies of a transgene in eastern white pine. J. Exp. Bot. 58: 545-554.

Vaisman BL (2013). Genotyping of transgenic animals by real-time quantitative PCR with TaqMan probes. Methods Mol. Biol. 1027: 233-251.

Van Reenen CG (2009). Assessing the welfare of transgenic farm animals. Genetic engineering in livestock: New applications and interdisciplinary perspectives 34: 119-143.

Wang Y, Song YT, Liu Q, Liu CE, et al. (2010). Quantitative analysis of lentiviral transgene expression in mice over seven generations. Transgenic Res. 19: 775-784.

Watanabe M, Kurome M, Matsunari H, Nakano K, et al. (2012). The creation of transgenic pigs expressing human proteins using BAC-derived, full-length genes and intracytoplasmic sperm injection-mediated gene transfer. Transgenic Res. 21: 605-618.

Williams A, Harker N, Ktistaki E, Veiga-Fernandes H, et al. (2008). Position effect variegation and imprinting of transgenes in lymphocytes. Nucleic Acids Res. 36: 2320-2329. 
Wu Z, Xu Z, Zou X, Zeng F, et al. (2013). Pig transgenesis by piggyBac transposition in combination with somatic cell nuclear transfer. Transgenic Res. 22:1107-1118.

Yan B, Li D and Gou K (2010). Homologous illegitimate random integration of foreign DNA into the X chromosome of a transgenic mouse line. BMC Mol. Biol. 11: 58 .

Yan BW, Zhao YF, Cao WG, Li N, et al. (2013). Mechanism of random integration of foreign DNA in transgenic mice. Transgenic Res. 22: 983-992.

Yuanxin Y, Chengcai A, Li L, Jiayu G, et al. (2003). T-linker-specific ligation PCR (T-linker PCR): an advanced PCR technique for chromosome walking or for isolation of tagged DNA ends. Nucleic Acids Res. 31: e68-e68.

Zhang R, Yin YL, Zhang YJ, Li KX, et al. (2012). Molecular characterization of transgene integration by next-generation sequencing in transgenic cattle. PLoS One 7: e50348.

Zhou Y, Lin Y, Wu X, Feng C, et al. (2013). The high-level accumulation of n-3 polyunsaturated fatty acids in transgenic pigs harboring the n-3 fatty acid desaturase gene from Caenorhabditis briggsae. Transgenic Res. 23: 89-97. 